\title{
Planar Extensional Viscosity Measurements for LDPE Polymer Melt by Using Novel Orifice Die Design and Cogswell Model
}

\author{
Martin Zatloukal \\ Centre of Polymer Systems, Polymer Centre, Tomas Bata University in Zlin, \\ nam. T. G. Masaryka 5555, 76001 Zlin, Czech Republic
}

\begin{abstract}
In this work, novel patent pending rectangle orifice die design has been proposed and tested for planar extensional viscosity measurements of extrusion coating LDPE through entrance pressure drop determination on conventional twin bore capillary rheometr. The obtained results have been compared with the corresponding uniaxial extensional viscosity data and different strain hardening level in both viscosities has been identified. It has been suggested that uniaxial and planar extensional viscosity measurements, utilizing novel orifice die design, can be considered as a very useful and simple tool to fulfill basic aims of the applied rheology.
\end{abstract}

Keywords: Orifice die, Planar extensional viscosity, Uniaxial extensional viscosity, Cogswell model, Entrance pressure drop, Polymer melts, Capillary rheometer.

PACS: 47.50.Ef, 83.50.Ha, 83.50.Jf, 83.60.Df, 83.80.Sg, 83.85.Cg, 83.85.Rx

\section{INTRODUCTION}

The extensional viscosity, characterizing the resistance of the fluid against the extensional flow, is one of the key rheological parameters which play a crucial role in manufacturing processes as well as it is very sensitive to the molecular structure of the fluid. Due to the fact that generation and control of the extensional flow is difficult, experimental determination of the extensional viscosity is a problem [1-2]. Different types of experimental techniques have been developed [1-16] to measure this very important property but each of them is applicable for only limited range of extensional rates or stresses. Probably the most challenging rheological task is experimental determination of planar extensional viscosity as one can see from very small numbers of experimental data available in the open literature $[1-2,12-16]$. In this work, novel patent pending orifice die has been developed and tested for planar extensional viscosity measurements by using standard twin bore capillary rheometer and Cogswell model $[6,12]$. 


\section{EXPERIMENTAL}

\section{Novel Orifice Die Design}

The sketch of the novel orifice die design for planar extensional viscosity measurements is depicted in Figure 1.
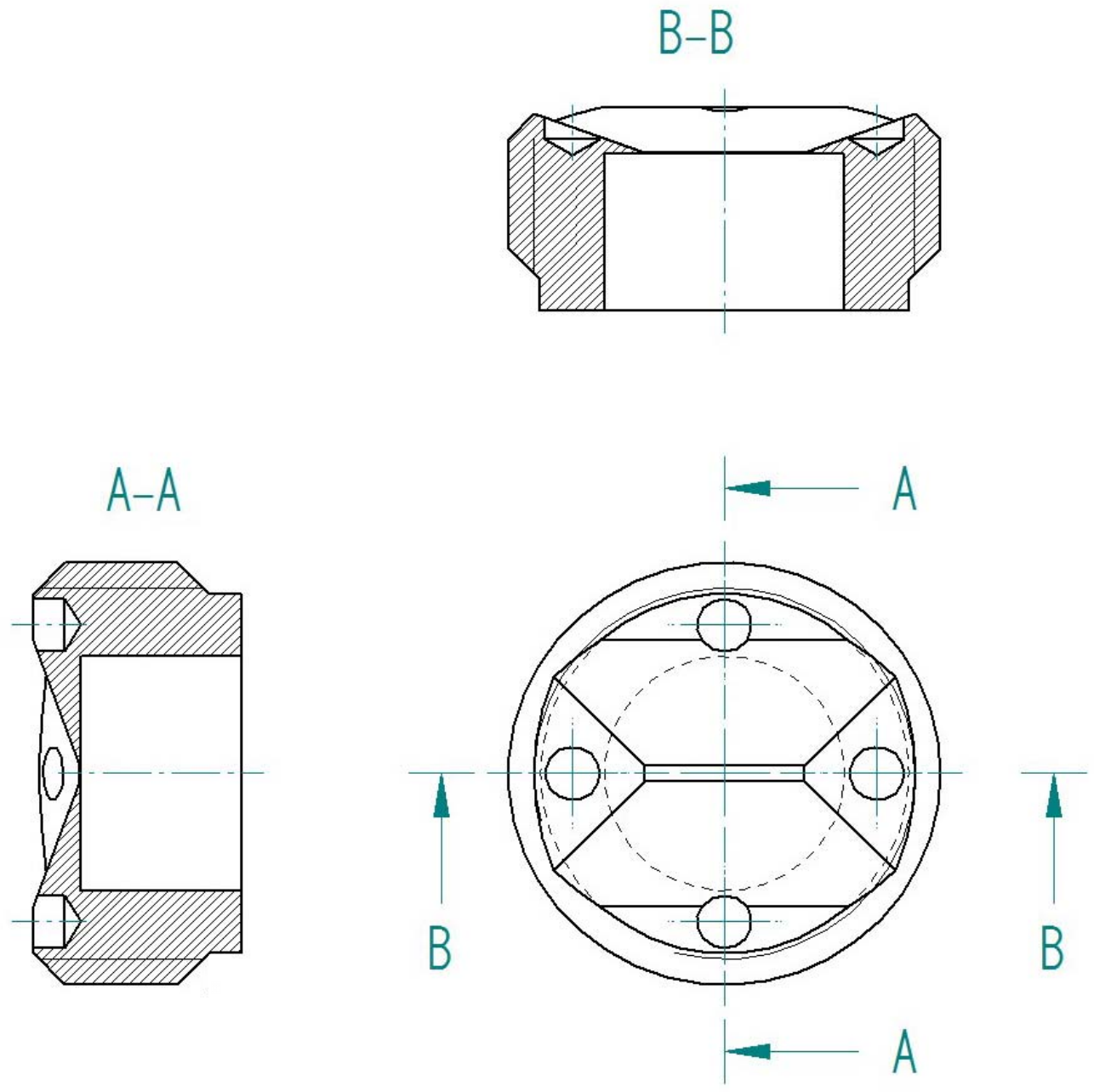

FIGURE 1. Sketch of the novel patent pending orifice die with abrupt entry for planar extensional viscosity measurements.

The proposed die design is characterized by the open downstream region which consists of highly diverging channel and four holes which enable to use special key to crew-up the orifice die to the rheometer barrel. This downstream orifice die geometry eliminates any possibility for artificial pressure increase due to polymer melt touching the downstream wall. 


\section{Experimental Evaluation of Novel Orifice Die Design}

Extrusion coating LDPE CA820 (MFR $=7.5 \mathrm{~g} / 10 \mathrm{~min}$ at $190^{\circ} \mathrm{C} / 2.16 \mathrm{~kg}$ ) from Borealis Polyolefine GmbH company together with Rosand RH7-2 twin bore capillary rheometer have been utilized for the experimental determination of planar extensional viscosity by using long die and novel orifice dies (both having rectangle flow channel) depicted in Figure 2.
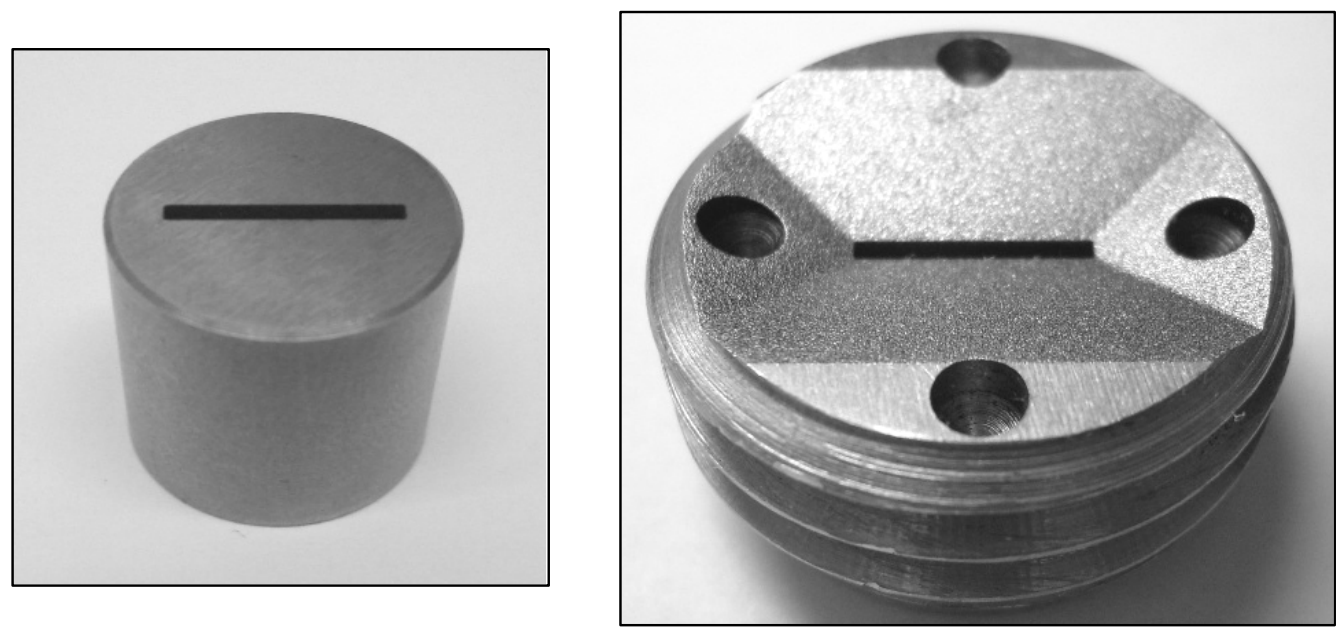

FIGURE 2. Set of patent pending dies for the planar extensional viscosity measurements on twin bore capilary rheometer which have been utilized in this work (left - long die, right - novel orifice die).

The uniaxial extensional viscosity data has been determined by using annular orifice die (CZ UV 19221) depicted in Figure 3.
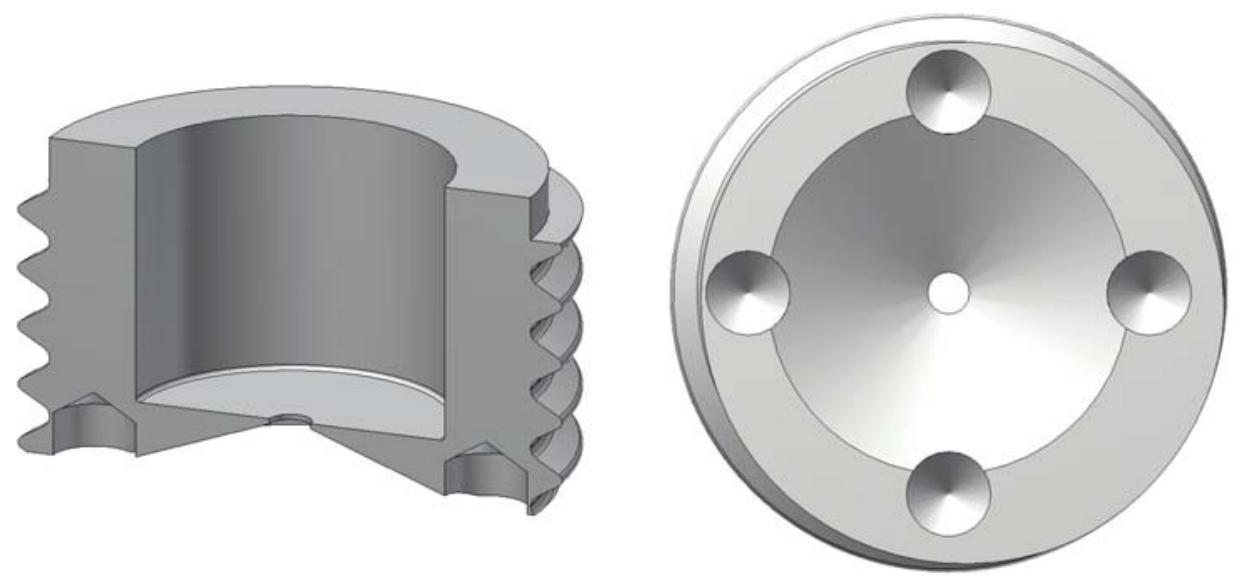

FIGURE 3. Sketch of the circular orifice die (CZ UV 19221) with abrupt entry for uniaxial extensional viscosity measurements developed in [11]. 
The uniaxial and planar extensional viscosities have been determined through entrance pressure drop measurements by using the Cogswell model $[6,12]$ (see Table 1).

Table 1. Cogswell model summarization for uniaxial/planar extensional viscosity determination $[6,12]$.

\begin{tabular}{lcc}
\hline & Uniaxial extensional flow & Planar extensional flow \\
\hline Apparent shear rate & $\dot{\gamma}_{\mathrm{app}, \mathrm{U}}=\frac{4 Q}{\pi R^{3}}$ & $\dot{\gamma}_{\mathrm{app}, \mathrm{P}}=\frac{6 Q}{w h^{2}}$ \\
Corrected shear stress & $\tau_{\mathrm{xy}, \mathrm{corr}, \mathrm{U}}=\frac{\left(P_{\mathrm{L}, \mathrm{U}}-P_{0, \mathrm{U}}\right) R}{2 L_{\mathrm{U}}}$ & $\tau_{\mathrm{xy}, \mathrm{corr}, \mathrm{P}}=\frac{\left(P_{\mathrm{L}, \mathrm{P}}-P_{0, \mathrm{P}}\right) h}{2 L_{\mathrm{P}}}$ \\
$\begin{array}{l}\text { Apparent index of non- } \\
\text { Newtonian behaviour }\end{array}$ & $n_{\mathrm{U}}=\frac{d \log \left(\tau_{\mathrm{xy}, \mathrm{corr}, \mathrm{U}}\right)}{d \log \left(\dot{\gamma}_{\mathrm{app}, \mathrm{U}}\right)}$ & $n_{\mathrm{P}}=\frac{d \log \left(\tau_{\mathrm{xy}, \mathrm{corr}, \mathrm{P}}\right)}{d \log \left(\dot{\gamma}_{\mathrm{app}, \mathrm{P}}\right)}$ \\
Extensional stress & $\sigma_{\mathrm{E}, \mathrm{U}}=\frac{3}{8}\left(n_{\mathrm{U}}+1\right) P_{0, \mathrm{U}}$ & $\sigma_{\mathrm{E}, \mathrm{P}}=\frac{1}{2}\left(n_{\mathrm{P}}+1\right) P_{0, \mathrm{P}}$ \\
Extensional strain rate & $\dot{\varepsilon}_{\mathrm{U}}=\frac{4 \tau_{\mathrm{xy}, \mathrm{corr}, \mathrm{U}} \dot{\gamma}_{\mathrm{app}, \mathrm{U}}}{3(n+1) P_{0, \mathrm{U}}}$ & $\dot{\varepsilon}_{\mathrm{U}}=\frac{2 \tau_{\mathrm{xy}, \mathrm{corr}, \mathrm{P}} \dot{\gamma}_{\mathrm{app}, \mathrm{P}}}{3(n+1) P_{0, \mathrm{P}}}$ \\
Extensional viscosity & $\eta_{\mathrm{E}, \mathrm{U}}=\frac{\sigma_{\mathrm{E}, \mathrm{U}}}{\dot{\varepsilon}_{\mathrm{U}}}$ & $\eta_{\mathrm{E}, \mathrm{P}}=\frac{\sigma_{\mathrm{E}, \mathrm{P}}}{\dot{\varepsilon}_{\mathrm{P}}}$ \\
\hline
\end{tabular}

Here $P_{0, \mathrm{U}}$ and $P_{0, \mathrm{P}}$ represents the entrance pressure drop measured on annular and rectangular orifice die, respectively, $Q$ is the volume flow rate, $R$ is the capillary die radius, $w$ and $h$ is the width and the gap size of the rectangle die, respectively, $P_{\mathrm{L}, \mathrm{U}}$ and $P_{\mathrm{L}, \mathrm{P}}$ represents the pressure drop through a long die having circular and rectangular shape, respectively, $P_{0, \mathrm{U}}$ and $P_{0, \mathrm{P}}$ is the orifice pressure drop having circular and rectangular shape, respectively, $L$ is the length of the long die. It should be mentioned that the long die has $L /(2 R)=16$ (or $L / h=16$ ) whereas the orifice die has $L /(2 R)=0.1208$ (or $L / h=0.1208)$ as suggested in [10].

\section{RESULTS AND DISCUSSION}

The comparison between the measured strain rate dependent uniaxial and planar extensional viscosities (together with the shear viscosity) for the tested extrusion coating LDPE CA820 sample is depicted in Figure 4. It is clearly visible that both planar and uniaxial extensional viscosities correctly follow $4 \eta_{0}$ and $3 \eta_{0}$ Trouton relationship, respectively, at low extensional strain rates. Interestingly, the level of the strain hardening in uniaxial extensional viscosity is much higher than in the planar extensional viscosity, which is more clearly visible in Figure 5 where normalized uniaxial and planar extensional viscosities are plotted as the function of the extensional strain rate. 


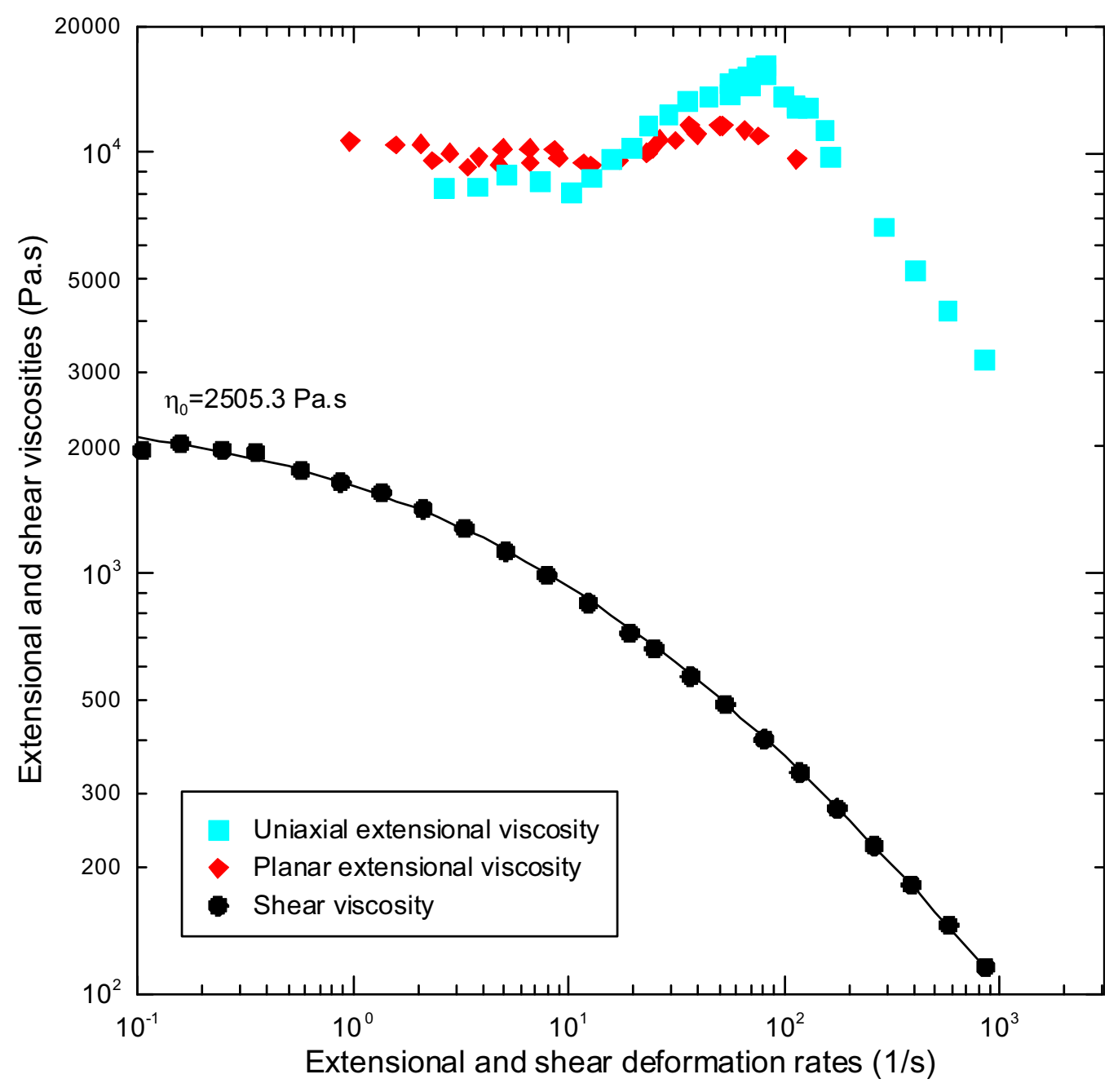

FIGURE 4. Comparison between measured strain rate dependent uniaxial and planar extensional viscosities (together with the shear viscosity) for the tested extrusion coating LDPE CA820 polymer sample at $190^{\circ} \mathrm{C}$.

Recently, it has been revealed [17-21] that the ratio of planar to uniaxial extensional viscosity, $\eta_{\mathrm{E}, \mathrm{P}} / \eta_{\mathrm{E}, \mathrm{U}}$, (i.e. the difference between the strain-hardening nature in planar and uniaxial elongation) controls the level of the unwanted neck-in phenomena (film width reduction occurring during the film casting process between the flat die and the chill/nip rolls) due to the fact that the middle of the film undergoes planar elongation whereas the material at the edge undergoes uniaxial elongation. Based on the film casting process modeling, the following relationship between neck-in, $N I$, and planar to uniaxial extensional viscosity ratio has recently been found [21]: 


$$
N I=\frac{1}{2}\left(W_{\mathrm{D}}-W_{\mathrm{F}}\right) \cong L\left\langle\frac{\eta_{\mathrm{E}, \mathrm{P}}}{\eta_{\mathrm{E}, \mathrm{U}}}\right\rangle_{L}^{1 / 2}
$$

where $W_{\mathrm{D}}$ represents the die exit width, $W_{\mathrm{F}}$ the final film width, respectively, $L$ is distance between the flat die and the chill/nip rolls and $\left\langle\eta_{\mathrm{E}, \mathrm{P}} / \eta_{\mathrm{E}, \mathrm{U}}\right\rangle$ is averaged planar to uniaxial extensional viscosity ratio. This suggests that the experimental evaluation of planar and uniaxial extensional viscosities can be considered as very useful tool for the film casting process optimization.

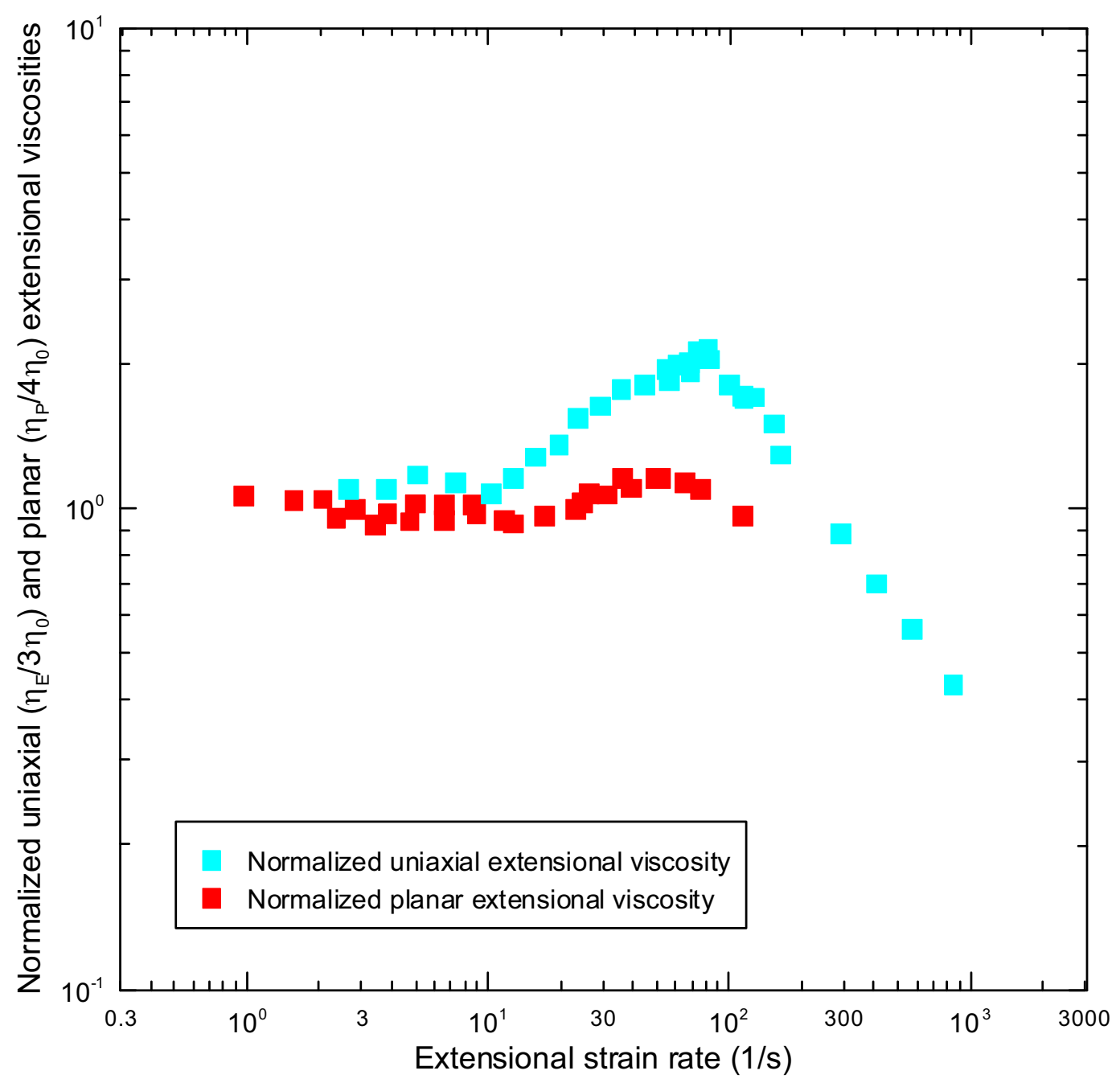

FIGURE 5. Comparison between normalized uniaxial and planar extensional viscosities for the tested extrusion coating LDPE CA820 polymer sample at $190^{\circ} \mathrm{C}$. 
It is believed that the proposed novel orifice die design for the planar extensional viscosity measurements can be considered as a very useful tool for better understanding of the polymer melt molecular structure, processing instabilities, optimization of polymer blends composition as well as for the constitutive equation testing purposes.

\section{CONCLUSION}

Novel patent pending rectangle orifice die design has been proposed and tested for the planar extensional viscosity measurements of extrusion coating LDPE through entrance pressure drop measurements on standard twin bore capillary rheometr. The obtained results have been compared with the corresponding uniaxial extensional viscosity data. It has been revealed that the level of the strain hardening in uniaxial extensional viscosity is higher than in the planar extensional viscosity for the particular tested sample. It is believed that the proposed rectangle orifice die design together with particular entrance pressure drop technique can be useful and simple tool to determine planar extensional viscosity for basic rheological purposes.

\section{ACKNOWLEDGMENTS}

The author wish to acknowledge Grant Agency of the Czech Republic (grant No. P108/10/1325, Grant No. 103/09/2066) and the Ministry of Education, Youth and Sports of the Czech Republic (MSM 7088352101) for the financial support. This article was written with support of Operational Program Research and Development for Innovations co-funded by the European Regional Development Fund (ERDF) and national budget of Czech Republic, within the framework of project Centre of Polymer Systems (reg. number: CZ.1.05/2.1.00/03.0111).

The authors also wish to acknowledge Assoc. Prof. Ing. Martin Obadal, Ph.D. from Borealis Polyolefine GmbH company for donation of the extrusion coating LDPE CA820 polymer, which has been used in this work.

\section{REFERENCES}

1. F. A. Morrison, Understanding Rheology, New York: Oxford University Press, 2001.

2. C. W. Macosko, Rheology: Principles, Measurements, and Applications, New York: Wiley-VCH, 1994.

3. H. Münstedt, J. Rheol. 23, 421-436 (1979).

4. M. L. Sentmanat, Rheol. Acta 43, 657-669 (2004).

5. M. L. Sentmanat, B. N. Wang and G. H. McKinley, J. Rheol. 49(3), 585-606 (2005).

6. F. N. Cogswell, Polym. Eng. Sci. 12, 64-73 (1972).

7. D. M. Binding, J. Non-Newtonian Fluid Mech. 27, 173-189 (1988).

8. A. G. Gibson, Composites 20, 57-64 (1989).

9. S. Kim and J. M. Dealy, J. Rheol. 45(6), 1413-1419 (2001).

10. M. Zatloukal, J. Vlcek, C. Tzoganakis and P. Saha, J. Non-Newtonian Fluid Mech. 107, 13-37 (2002). 
11. M. Zatloukal and J. Musil, Polym. Test. 28(8), 843-853 (2009).

12. K. Walczak, M. Gupta, K. A. Koppi, J. Dooley and M. A. Spalding, Polym. Eng. Sci. 48, 223-232 (2008).

13. H. M. Laun and H. Schuch, J. Rheol. 33(1), 119-175 (1989).

14. M. Kraft, "Untersuchungen zur scherinduzierten rheologischen Anisotropie von verschiedenen Polyethylen- Schmelzen”, Ph.D. Thesis, Dissertation ETH Zurich Nr. 11417, 1996.

15. P. Hachmann, "Multiaxiale Dehnung von Polymerschmelzen“, Ph.D. Thesis, Dissertation ETH Zurich Nr. 11890, 1996.

16. J. Meissner, S. E. Stephenson, A. Demarmels and P. Portman, J. Non-Newtonian Fluid Mech. 11(3-4), 221-237 (1982).

17. T. Dobroth and L. Erwin, Polym. Eng. Sci. 26(7), 462-467 (1986).

18. N. Satoh, H. Tomiyama and T. Kajiwara, Polym. Eng. Sci. 41(9), 1564-1579 (2001).

19. T. Kajiwara, M. Yamamura and T. Asahina, Nihon Reoroji Gakkaishi 34(2), 97-103 (2006).

20. S. Shiromoto, Y. Masutani, M. Tsutsubuchi, Y. Togawa and T. Kajiwara, Polym. Eng. Sci. 50(1), 22-31 (2010).

21. S. Shiromoto, Y. Masutani, M. Tsutsubuchi, Y. Togawa and T. Kajiwara, Rheol. Acta 49, 757-767 (2010). 
Copyright of AIP Conference Proceedings is the property of American Institute of Physics and its content may not be copied or emailed to multiple sites or posted to a listserv without the copyright holder's express written permission. However, users may print, download, or email articles for individual use. 